Article

\title{
The Effect of Chlorogenic Acid on Bacillus subtilis Based on Metabolomics
}

\author{
Yan Wu ${ }^{1,2, \dagger}$, Shan Liang ${ }^{1,2,+}$, Min Zhang ${ }^{1,2, *}$, Zhenhua Wang ${ }^{1,2}$, Ziyuan Wang ${ }^{1,2} \mathbb{D}$ \\ and Xin Ren ${ }^{1,2}$ \\ 1 Beijing Advanced Innovation Center for Food Nutrition and Human Health, Beijing Technology and \\ Business University, Beijing 100048, China; 10011216006@st.btbu.edu.cn (Y.W.); liangshan@btbu.edu.cn (S.L.); \\ zhwang@btbu.edu.cn (Z.W.); wangziyuan@btbu.edu.cn (Z.W.); 20180734@btbu.edu.cn (X.R.) \\ 2 Beijing Engineering and Technology Research Center of Food Additives, Beijing Technology and Business \\ University, Beijing 100048, China \\ * Correspondence: zmin@th.btbu.edu.cn; Tel.: +86-13611099470 \\ + These authors contributed equally to this work.
}

Received: 15 August 2020; Accepted: 3 September 2020; Published: 4 September 2020

\begin{abstract}
Chlorogenic acid (CGA), a natural phenolic compound, is an important bioactive compound, and its antibacterial activity has been widely concerned, but its antibacterial mechanism remains largely unknown. Protein leakage and the solution exosmosis conductivity of Bacillus subtilis 24434 (B. subtilis) reportedly display no noticeable differences before and after CGA treatment. The bacterial cells treated with CGA displayed a consistently smooth surface under the electron microscope, indicating that CGA cannot directly disrupt bacterial membranes. However, CGA induced a significant decrease in the intracellular adenosine triphosphate (ATP) concentration, possibly by affecting the material and energy metabolism or cell-signaling transduction. Furthermore, metabolomic results indicated that CGA stress had a bacteriostatic effect by inducing the intracellular metabolic imbalance of the tricarboxylic acid (TCA) cycle and glycolysis, leading to metabolic disorder and death of B. subtilis. These findings improve the understanding of the complex action mechanisms of CGA antimicrobial activity and provide theoretical support for the application of CGA as a natural antibacterial agent.
\end{abstract}

Keywords: chlorogenic acid; Bacillus subtilis; antimicrobial activity; metabolomics

\section{Introduction}

Chlorogenic acid (CGA) is an important phenolic compound belonging to the hydroxycinnamic acid derivative family and consists of caffeic acid and quinic acid via esterification [1,2]. CGA is abundantly present in coffee beans [3], fruits [4], vegetables [5], and herbs [6] and displays antibacterial, antiphlogistic, antimutagenic, antioxidant, and other biological activities [7,8]. Studies are directing increasing focus toward the extraction, separation, and antibacterial activity of CGA in a variety of plants [9], indicating that this compound is effective against certain microorganisms [10]. Kim and Li et al. [11,12] confirmed that CGA displayed an antimicrobial effect, while Li et al. [12] indicated that the minimum inhibitory concentration (MIC) of CGA against Staphylococcus aureus was $2.5 \sim 5.0 \mathrm{mg} / \mathrm{mL}$. Sung et al. [5] concluded that CGA exhibited anti-fungal activity, while the research conducted by Wang et al. [13] involving the antibacterial effect of tobacco CGA extract showed a certain inhibitory effect on Escherichia coli and Bacillus subtilis. Lou et al. [14] reported that the MIC for CGA against B. subtilis was $40 \mu \mathrm{g} / \mathrm{mL}$. Su et al. [15] indicated that the MIC of CGA against Pseudomonas fluorescein and Staphylococcus saprophytes from chicken was $5 \mathrm{mg} / \mathrm{mL}$. Currently, it is speculated that the way in which the structure and function of CGA affects its antimicrobial activity occurs as follows: (1) CGA molecule contains phenolic hydroxyl, which can affect the activity of related metabolic enzymes, reduce 
the metabolic level, cause the metabolic process to be blocked, and inhibit the activity of bacteria [16]. (2) CGA molecules display strong polarity and can bind to large molecules, such as lipids, on the surface of bacteria to change the permeability of the bacterial membrane, resulting in the leakage of the contents $[14,17]$. (3) CGA may inhibit bacterial flagella synthesis, reduce the number of flagella, and thus reduce the bacterial clustering effect [18].

Food spoilage, in a broad sense, is a change in the chemical or physical properties of food caused by microorganisms, which poses a serious threat to food safety [19]. However, the reproduction of microorganisms on both the exterior and interior of food is the most common cause of food spoilage [20]. Food spoilage Bacillales members are typically assigned to the Bacillus, Geobacillus, Anoxybacillus, Alicyclobacillus, and Paenibacillus genera [21]. The Gram-positive bacteria responsible for spoilage in meats are Clostridium, Bacillus, and Lactic acid bacteria [22]. Xu et al. [23] isolated and identified the dominant bacteria causing fresh noodle corruption and found that the dominant strains causing instant wet surface deterioration were mainly Bacillus subtilis, Bacillus licheniformis, and Bacillus giganteum. Li et al. [24] found that Bacillus licheniformis and Bacillus subtilis were the dominant bacterial strains during the early stages of storage. Therefore, according to previous studies, Bacillus subtilis displays a strong ability to hydrolyze starch and protein, while this microorganism commonly causes food spoilage.

The metabolome, which refers to the systematic analysis of the small molecule metabolites in microbial compositions and dynamic responses [25], encompasses a diverse array of molecular chemotypes, including peptides, carbohydrates, lipids, nucleosides, and catabolic products of exogenous compounds [26]. The metabonomic analysis is used to assess the series of changes occurring under external stress or pathological damage [27], while metabolites directly reveal a life of phenotypic change in the system [28].

Therefore, the study of the changes in intracellular metabolites assists in understanding the effect of CGA on microbial metabolism, attempting to elucidate the antibacterial activity of CGA further. Accordingly, this study clarifies the effect of CGA on B. subtilis by examining the effect of bacteriostatic agents at different concentrations on bacterial metabolites, while conducting an extensive investigation into the bacteriostatic activity. Consequently, this study provides a theoretical basis for the development and utilization of CGA bacteriostatic agents.

\section{Results and Discussion}

\subsection{MIC}

In this study, the MIC values for CGA was $2.50 \mathrm{mg} / \mathrm{mL}$. However, Lou et al. [14] reported that the MIC for CGA against B. subtilis was $40 \mu \mathrm{g} / \mathrm{mL}$, which was lower than the value calculated in this study. Su et al. [15] indicated that the MIC of CGA against Pseudomonas fluorescein and Staphylococcus saprophytes was $5 \mathrm{mg} / \mathrm{mL}$. A possible reason is that different CGA extraction conditions and variations in the inoculum level, experimental temperature, and physiological condition of the bacteria used in different studies may affect its antibacterial activity.

\subsection{Scanning Electron Microscope (SEM) and Membrane Permeability Assay}

Any morphological changes in the tested strains treated with CGA were observed with SEM to observe the damage to the cell structure. Figure 1A shows that the untreated bacteria exhibited bacilliform morphology, and the surface appeared plump and intact. The bacterial cells treated with CGA at MIC values were slightly damaged compared with the control and 0.5 MIC CGA cells treated, which had a smooth surface. The release of intracellular proteins and changes in conductivity can be regarded as an indication of cell structure integrality [29]. Figure 1B shows that there was no significant change in protein leakage before and after CGA treatment. The effect on the cell membrane in response to CGA treatment was also observed through relative permeability (Figure 1C). The relative conductivity of $B$. subtilis did not increase substantially after CGA treatment, while displaying no 
significant differences from the control group. The results showed that CGA treatment had a negligible effect on the cell membrane of B. subtilis.

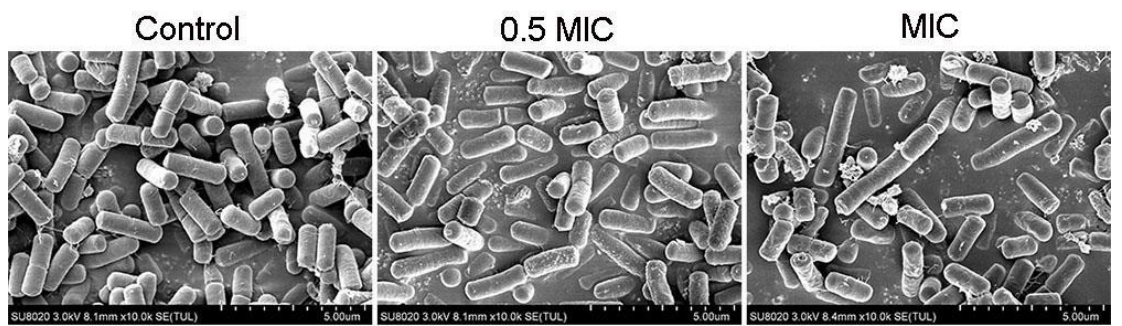

(A)

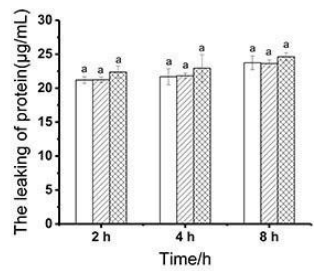

(B)

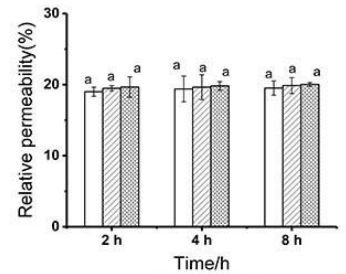

(C)

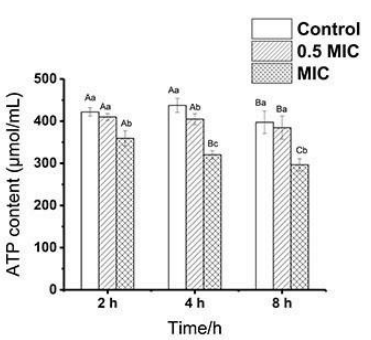

(D)

Figure 1. Effect of different chlorogenic acid (CGA) concentrations on B. subtilis: (A) SEM images; (B) protein leakage; (C) the change in relative permeability; (D) intracellular ATP content. The values represent the means of three reproducible experiments. (Capital letters indicate the significance of differences at different times, while lowercase letters indicate the significance of differences between samples at the same time.).

ATP represents the direct energy source in organisms. Figure 1D shows the effect of different CGA concentrations on the intracellular ATP levels in the B. subtilis cells, which was $420.01 \mu \mathrm{mol} / \mathrm{mL}$ in the control group. In comparison, B. subtilis treated MIC CGA showed a significant $(p<0.05)$ reduction in the intracellular ATP concentrations, while exposure to MIC CGA produced a value of $358.49 \mu \mathrm{mol} / \mathrm{mL}$ in ATP levels. Compared with MIC CGA, 0.5 MIC CGA induced a decrease in the intracellular ATP concentrations, which was lower than CGA treatment alone. Since the cell membrane was not damaged, the decrease in ATP was probably caused by the influence of CGA on the intracellular metabolism or intracellular signal transduction. Therefore, the changes in intracellular metabolism were detected after CGA treatment.

\subsection{The Intracellular Metabolites of B. subtilis}

A total of 81 intracellular metabolites with known structures were identified in B. subtilis after CGA treatment at different concentrations (Table 1). These included amino acids, organic acids, phosphoric compounds, cofactors, and nucleotides, as well as hormones and secondary metabolites. The highest number of intracellular metabolites detected in this study were also reported in the metabolomics studies conducted by Ding et al. [27] and Bo et al. [30].

Principal component analysis (PCA), an unsupervised clustering method, was used to process the data to verify the observations further and identify the metabolites primarily responsible for the discrimination between the cells treated with CGA and the control cells. The results indicated that the cumulative contribution rate of the first seven principal components was $81.62 \%$, which reflected the primary variable data. As shown in Figure 2, the score plots of both the first principal component (P1) and the second principal component (P2) depicted a clustering of samples. In the PCA score chart $(\mathrm{R} 2 \mathrm{X}=0.504)$, the horizontal and vertical coordinates were $\mathrm{P} 1$ and $\mathrm{P} 2$, while the contribution rates of these two principal components were 0.397 and 0.107 , respectively. The CGA-treated samples were distinctly different from the control group. The results suggested that CGA had a noticeable effect on 
cell metabolism, which again confirmed that the inhibition of $B$. subtilis by CGA might be achieved by restricting the metabolism.

Table 1. Intracellular metabolites in B. subtilis before and after CGA treatment as detected with LC-MS.

\begin{tabular}{|c|c|c|c|c|c|}
\hline NO. & Compound Name & NO. & Compound Name & NO. & Compound Name \\
\hline 1 & Citric acid & 28 & L-Arginine & 55 & ADP \\
\hline 2 & Cis-Aconitic acid/suberic acid & 29 & L-Aspartic acid & 56 & CDP \\
\hline 3 & Isocitric acid & 30 & L-Glutamic acid & 57 & Cyclic AMP \\
\hline 4 & Oxoglutaric acid & 31 & L-Glutamine & 58 & Cyclic GMP \\
\hline 5 & Succinyl-CoA & 32 & L-Histidine & 59 & Cytidine triphosphate- 1 \\
\hline 6 & Succinic acid & 33 & L-Isoleucine & 60 & Guanine \\
\hline 7 & Fumaric acid & 34 & Azelaic acid & 61 & Guanosine \\
\hline 8 & Malic acid & 35 & D-2-Hydroxyglutarate & 62 & Guanosine diphosphate \\
\hline 9 & Oxalacetic acid & 36 & Malonic acid & 63 & Guanosine monophosphate-2 \\
\hline 10 & Glucose 6-phosphate & 37 & Glutaric acid & 64 & Guanosine triphosphate \\
\hline 11 & Fructose 6-phosphate & 38 & Salicylic acid & 65 & Hypoxanthine \\
\hline 12 & Fructose 1,6-bisphosphate & 39 & Phenylacetic acid & 66 & IDP \\
\hline 13 & Dihydroxyacetone phosphate & 40 & Glucose 1-phosphate & 67 & Inosine \\
\hline 14 & 3-Phosphoglycerate & 41 & Deoxyuridine triphosphate & 68 & Inosinic acid(IMP) \\
\hline 15 & Phosphoenolpyruvic acid & 42 & Glycerol 3-phosphate & 69 & Pimelic acid/2-oxoadipate \\
\hline 16 & Pyruvic acid- 1 & 43 & Sedoheptulose 1,7-bisphosphate & 70 & Putrescine \\
\hline 17 & L-Lactic acid & 44 & Sedoheptulose 7-phosphate & 71 & Pyridoxal phosphate \\
\hline 18 & L-Leucine & 45 & Ribose-5-phosphate & 72 & Tryptamine \\
\hline 19 & L-Lysine & 46 & Fructose 1-phosphate & 73 & Tyramine \\
\hline 20 & L-Methionine & 47 & Orotic acid & 74 & Uracil \\
\hline 21 & L-Phenylalanine & 48 & Oxalic acid & 75 & Uridine $5^{\prime}$-diphosphate \\
\hline 22 & L-Proline & 49 & Pantothenic Acid & 76 & Uridine diphosphate glucose \\
\hline 23 & L-Serine & 50 & Nicotinic acid-1 & 77 & Uridine diphosphate glucuronic acid \\
\hline 24 & L-Threonine & 51 & 4-Hydroxybenzaldehyde & 78 & Uridine triphosphate \\
\hline 25 & L-Tyrosine & 52 & 4-Hydroxybenzoic acid & 79 & Xanthine \\
\hline 26 & L-Valine & 53 & Adenosine diphosphate ribose & 80 & Xanthosine \\
\hline 27 & L-Alanine & 54 & Adenosine triphosphate & 81 & Xanthylic acid \\
\hline
\end{tabular}

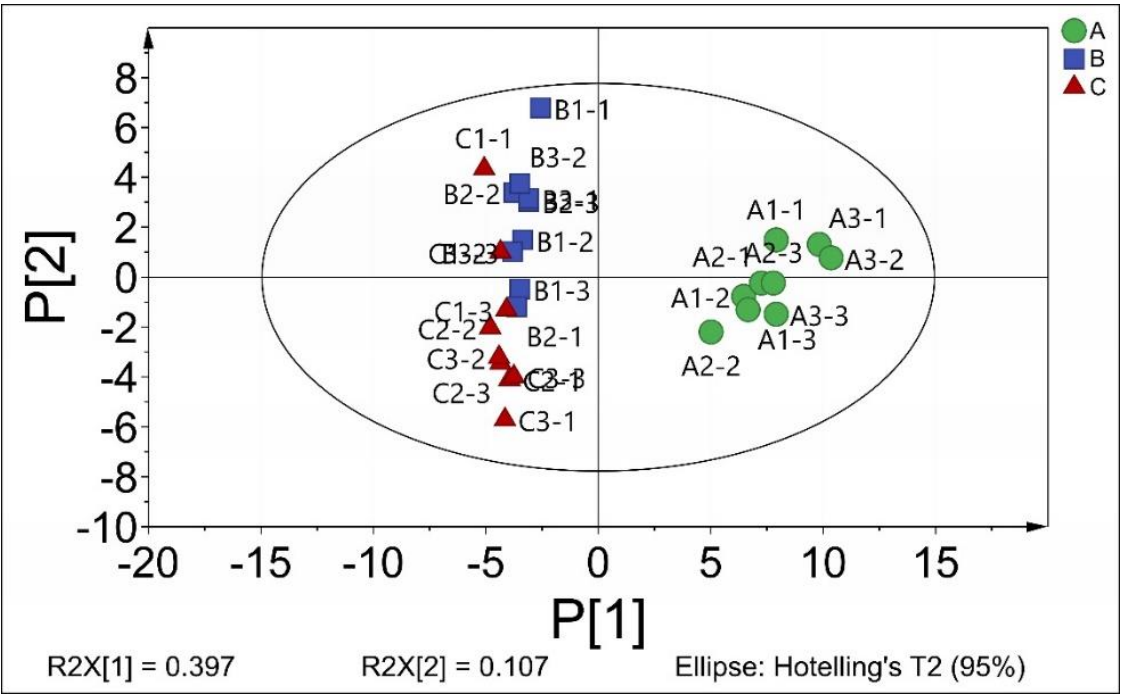

Figure 2. Principal component analysis (PCA) of the effect of different CGA concentrations on the metabolites of B. subtilis: A (Control); B (0.5 MIC); C (MIC). MIC = minimum inhibitory concentration.

Hierarchical cluster analysis (HCA) was employed to perform a preliminary assessment of the samples, and the obtained heatmap (Figure 3) not only reflected the differences and similarities between the various samples but also showed the content diversity of the 81 metabolites following the addition of CGA. The compositional differences between the concentrations were much more pronounced during HCA. The heatmap indicated that the addition of CGA led to significant differences between each experimental group and the control group, while differences were evident in the B. subtilis cell metabolic map before and after CGA treatment. Compared with the control group, the level of intracellular metabolites declined after the addition of CGA. The content of 37 metabolites decreased significantly after CGA treatment, which included citric acid, malonic acid, and glycerol 3-phosphate, among others. These metabolites affected several metabolic pathways, such as glycolysis, tricarboxylic 
acid (TCA) metabolism, amino acid metabolism, pentose phosphate, and pyrimidine metabolism, while increasing the orotic acid and putrescine content. Putrescine is a regulatory metabolic substance that can interact with negatively charged nucleic acids, membrane proteins, and other biological macromolecules, resulting in a series of physiological or pathological changes in the cell. This study observed that compared with the control group, the addition of CGA induced either an increase or a decrease in the bacterial metabolite content, leading to the metabolic disorder and death of bacteria. Based on the variation in metabolite concentration, combined with the experimental results of CGA regarding membrane integrity, CGA at $0.5 \mathrm{MIC}$ level had no significant effect on membrane integrity but had a considerable impact on intracellular metabolite concentration. Therefore, CGA can inhibit bacterial growth and even cause death by affecting the metabolic pathways.
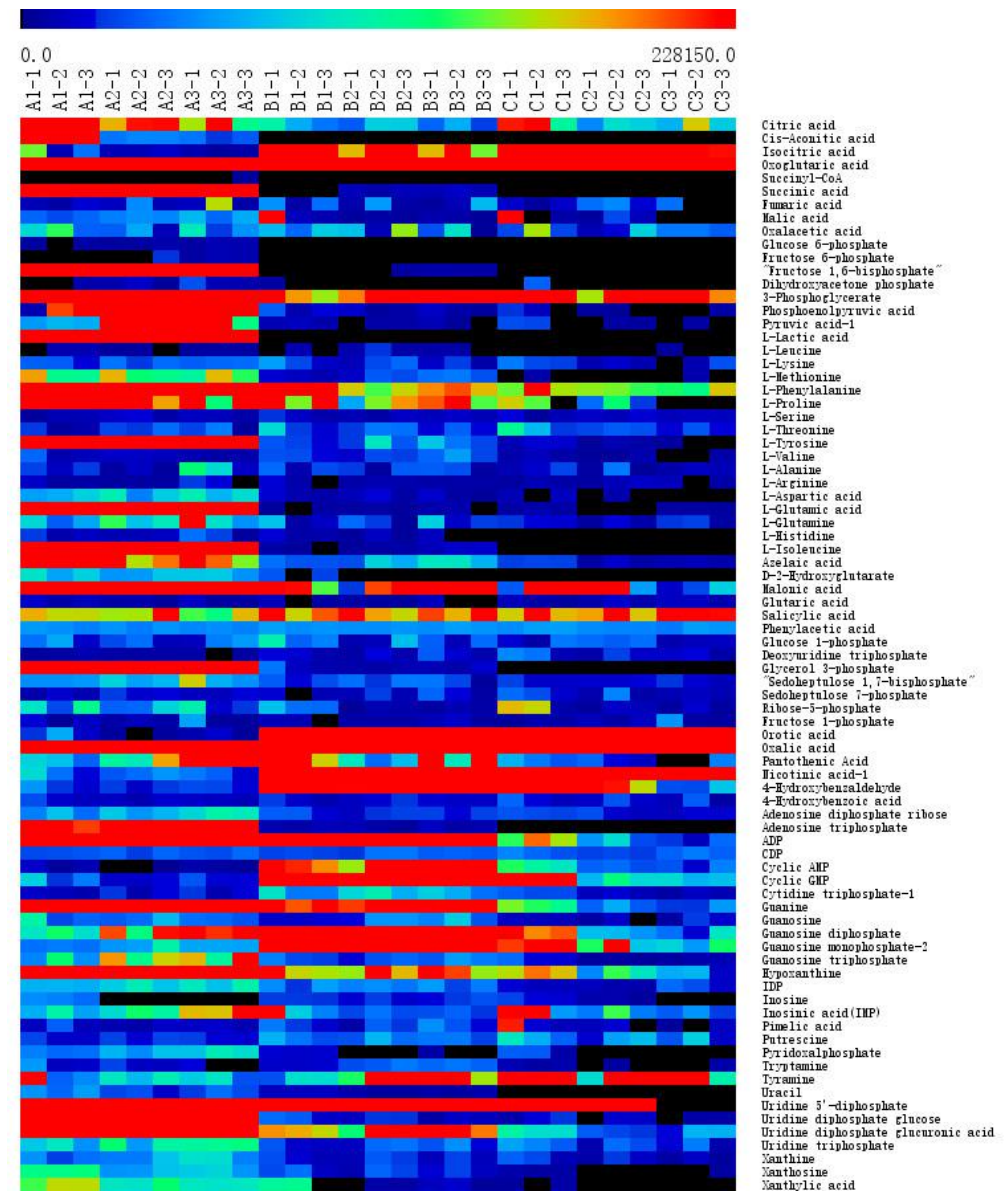

Figure 3. Heat map representation of the effect of different CGA concentrations on the $B$. subtilis metabolites. A: Control group; B: 0.5 MIC-treated group; C: MIC-treated group: A (Control); B (0.5 MIC); $\mathrm{C}(\mathrm{MIC})$.

The metabolites of the individual CGA-treated and control groups were clustered and could be discriminated from each other with the multivariate statistical method, orthogonal partial least squares discriminant analysis (OPLS-DA) [31]. After cross-validation via pali-pair comparison, the differential metabolites were screened using a load graph, while a shared and unique structure (SUS)-plot model was adopted for screening these metabolites among the three groups. Furthermore, the differences in the metabolites of the B. subtilis concentrations after CGA treatment were also determined (Figure 4). From the results, most of the intracellular metabolites changes with CGA concentration and can be divided into glycolysis, purine metabolism, amino acids, and carbohydrates according to the metabolic pathway or function. Furthermore, it is believed that CGA treatment can block the transformation of key metabolites in the pathway and cause the metabolic imbalance of small cell molecules, therefore, 
affecting bacterial activity. Halouska and Fenton et al. [32] employed OPLS-DA to profile the in vivo action mechanism of known antibiotics used to treat $M$. tuberculosis.

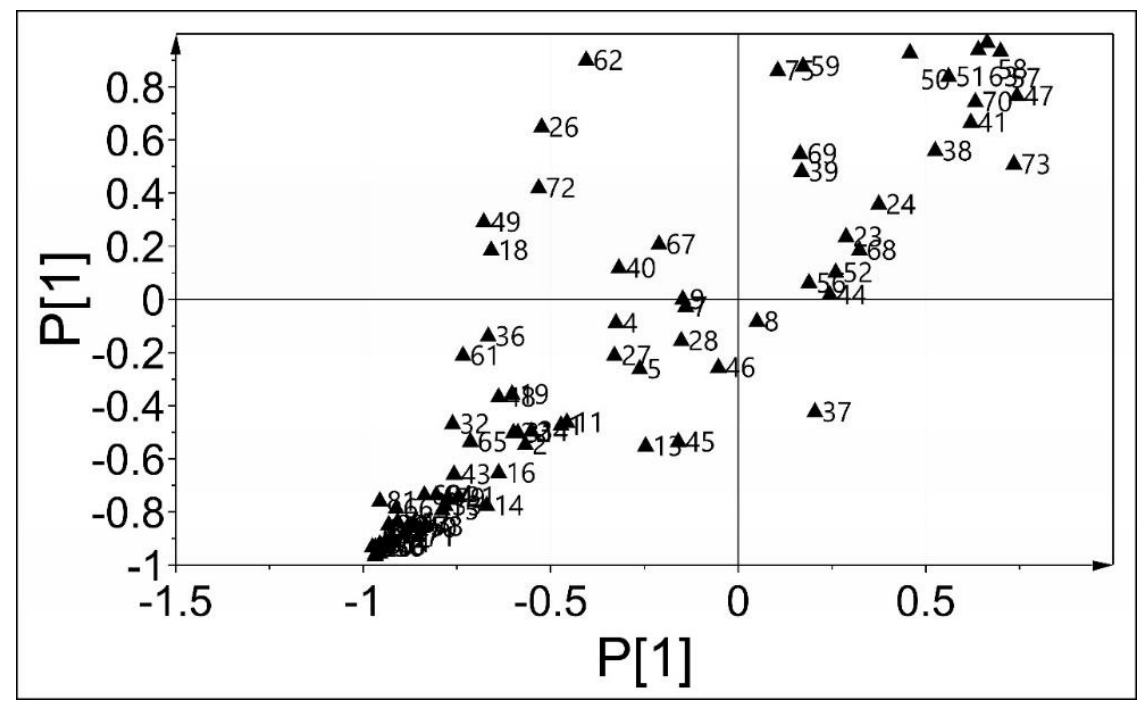

Figure 4. SUS-plot differentiating the effect of various CGA concentrations on B. subtilis metabolites.

\subsection{The Effect of CGA on the Primary Metabolism of B. subtilis}

The measured metabolite variations were mapped onto the metabolic pathways (Figure 5) to investigate potential links between the metabolic changes and CGA treatment. The TCA cycle forms a crucial part of the metabolic pathways of all aerobic organisms during the generation of energy [33]. Compared with the experimental group, the citrate, cis-aconitate, isocitrate, succinate, and other substances changed significantly during the TCA cycle. During glycolysis, glucose 6-phosphate, and fructose 1, 6-diphosphate were significantly reduced in the CGA-treated group compared with the control group. Citrate, cis-aconitate, and succinate are related to the TCA cycle. After $2 \mathrm{~h}$, the citrate and cis-aconitate levels decreased dramatically in the CGA-treated group compared with the control group, while the succinate levels showed a marked decrease in the 0.5 MIC and MIC CGA-treated groups, respectively. Tao et al. [30] suggested that the cause of the pathway changes after CGA treatment might be related to the inhibition of the metabolic level of the B. subtilis TCA cycle by CGA. Therefore, CGA reportedly affected the bacterial metabolism, resulting in insufficient energy for the bacteria, while impacting their growth and reproduction [34].

Changes in amino acids, which play a critical role in cells and participate in a variety of life activities, may affect the normal functionality of cells. We show examples of 15 amino acids that differed significantly between the three groups in Figure 6, including L-Lysine (Lys), L-Methionine (Met), L-Phenylalanine (Phe), L-Proline (Pro), L-Serine (Ser), L-Tyrosine (Tyr), L-Alanine (Ala), L-Arginine (Arg), L-Aspartic acid (Asp), L-Glutamate (Glu), L-Histidine (His), and L-Isoleucine (Ile). Met, Phe, Tyr, Asp, Glu, and Ile were substantially higher in the control group than in CGA-treated groups. Glu is associated with the carbon and nitrogen balance of cells, while the synthesis of nitrogen compounds in cells generally requires glutamate to provide a nitrogen source [35]. Higher levels of asparagine often correlate with differences in the carbon/nitrogen balance. Metabolites, including Ser, phenylalanine, Leu, Ile, and Val, can be converted from 3-P-glycerate and pyruvate, which are both metabolic intermediates of the Embden-Meyerhof-Parnas (EMP) pathway [30]. In previous studies, the S. cerevisiae EMP pathway was also inhibited by phenol, acetic acid, and other external stimulants $[27,36]$ as the levels of the metabolic intermediates of the EMP pathway decreased under CGA treatment. These results also indicated the inhibition of the EMP pathway by CGA. 


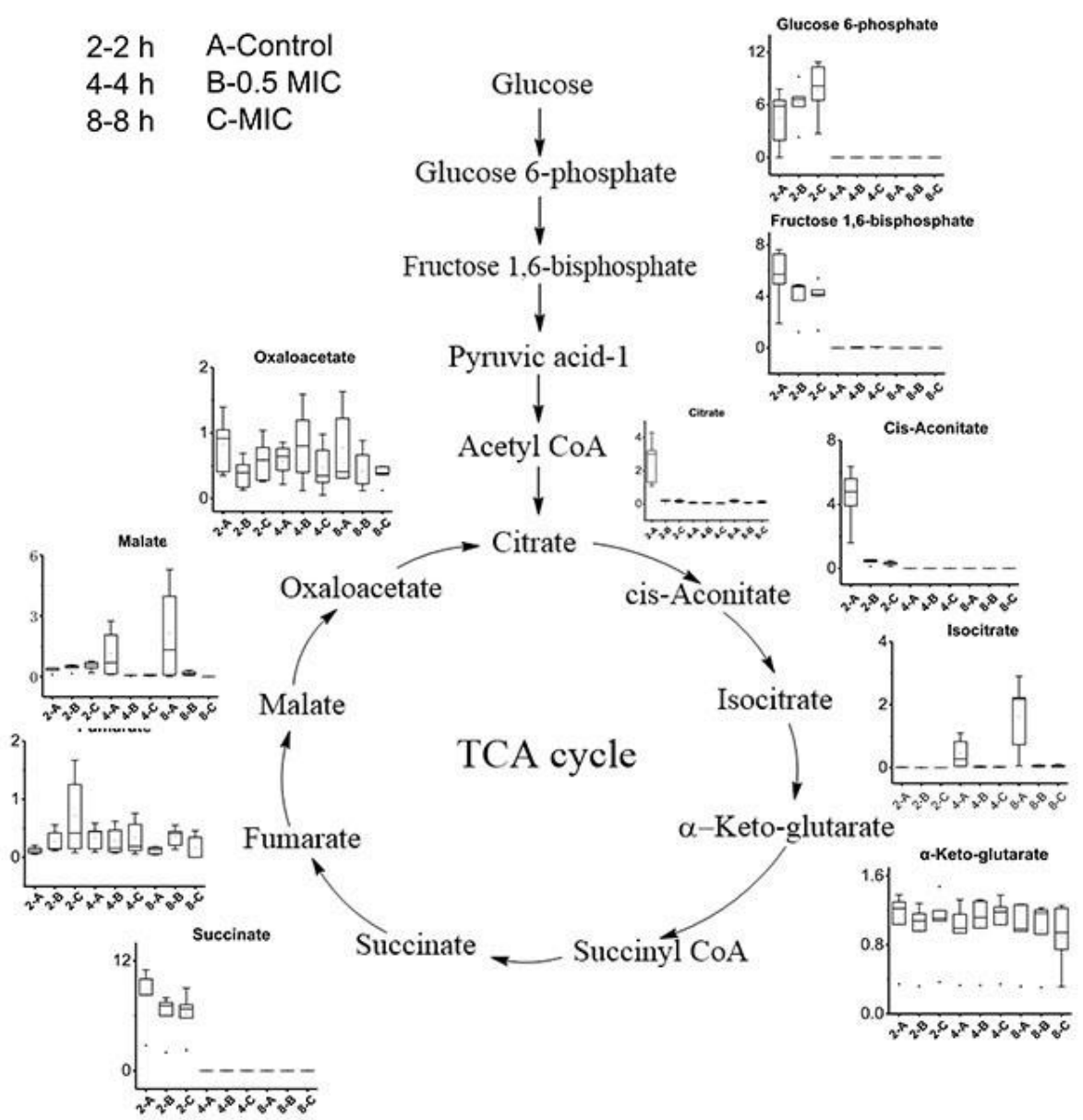

Figure 5. Schematic showing changes in metabolite abundance, which was mapped using the main metabolic network at sampling times of 2,4 , and $8 \mathrm{~h}$.

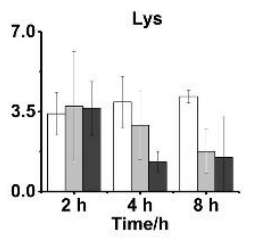

Ser

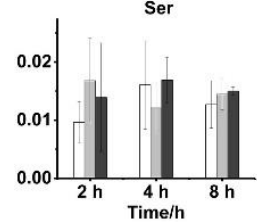

Glu

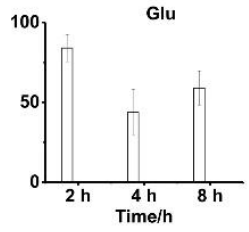

Thr

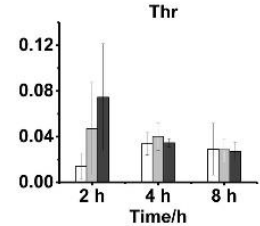

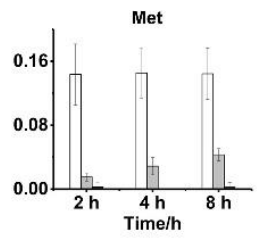

Tyr

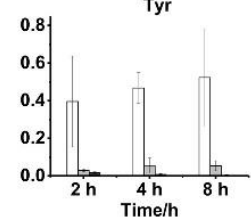

Asp

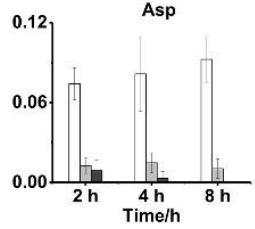

Val

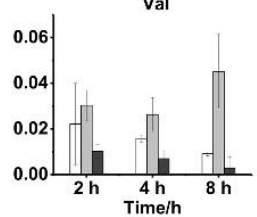

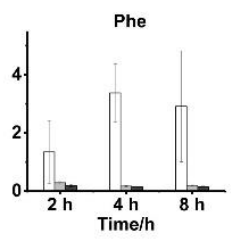

Ala

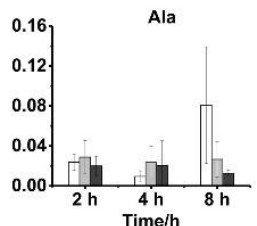

His

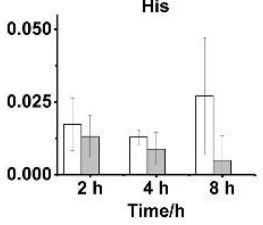

Leu

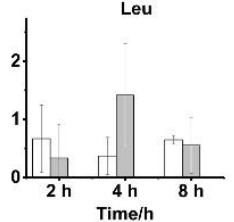

Pro

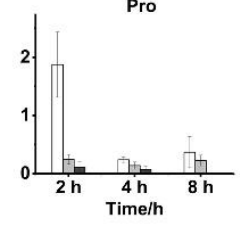

Arg
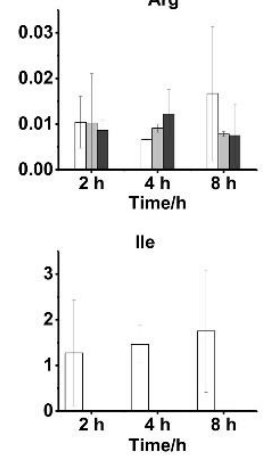

$0.5 \mathrm{MIC}$

Figure 6. Amino acid variations under the influence of CGA at 2, 4, and $8 \mathrm{~h}$. 


\section{Materials and Methods}

\subsection{The Reagent and Bacterial Strains}

B. subtilis was obtained from the China Center of Industrial Culture Collection (CICC). Luria-Bertani (LB) medium (5 g beef extract, $10 \mathrm{~g}$ peptone, $10 \mathrm{~g} \mathrm{NaCl}$, and $1000 \mathrm{~mL} \mathrm{H}_{2} \mathrm{O}$, at $\mathrm{pH} 7.2$ ). A stock solution of $10.0 \mathrm{mg} / \mathrm{mL}$ CGA (95\% purity, Shanghai Yuanye Bio-Technology Co., Ltd., Shanghai, China) was prepared.

\subsection{Determination of MIC}

The MIC of the antimicrobials was determined using the standard broth microdilution method [37], with some modifications. B. subtilis was incubated in LB medium at $37{ }^{\circ} \mathrm{C}$ for $8-10 \mathrm{~h}$ to reach approximately $10^{6} \mathrm{CFU} / \mathrm{mL}$. Serial dilutions of CGA were prepared in an LB medium to obtain final concentrations of $5 \mathrm{mg} / \mathrm{mL}, 2.5 \mathrm{mg} / \mathrm{mL}, 1.25 \mathrm{mg} / \mathrm{mL}, 0.625 \mathrm{mg} / \mathrm{mL}, 0.3125 \mathrm{mg} / \mathrm{mL}$, and $0.15625 \mathrm{mg} / \mathrm{mL}$. The plates were incubated for up to $24 \mathrm{~h}$ before recording the MICs. Samples incubated without antimicrobials were used as controls.

\subsection{The Detection of Extracellular Protein}

The activated indicator bacteria were inoculated into an LB medium at a volume concentration of $2 \%$ and cultured to the logarithmic phase after which it was centrifuged and resuspended in phosphate-buffered saline (PBS) buffer at pH 7.4. CGA at a concentration of $1 \times$ MIC was added to the culture for $2 \mathrm{~h}$ and centrifuged after which the supernatant was collected for use. The Bradford method was used to determine the absorbance at $595 \mathrm{~nm}$, while the protein concentration was calculated according to the protein standard curve and the sample volume. The experiment was repeated three times with the indicator bacteria and PBS ( $\mathrm{pH} 7.4)$ buffer as the control group. Please refer to the instruction manual of the test kit for determining the mass protein concentration.

\subsection{SEM Assay}

SEM was used to observe the morphological changes in B. subtilis after CGA treatment with 0.5 MIC and MIC. Logarithmic phase bacteria were exposed to different concentrations of CGA for 2,4, and $8 \mathrm{~h}$ after which the cells were washed with PBS following incubation and fixed for $1 \mathrm{~h}$ at $4{ }^{\circ} \mathrm{C}$ with $2.5 \%$ glutaraldehyde. The samples were dehydrated in sequential ethanol, freeze-dried with a vacuum freeze dryer, coated using an ion sputtering apparatus (Hitachi MC 10,003), and observed with SEM (Hitachi SU8020, Hitachi Productions Inc., Tokyo, Japan). The bacterial cells that were not treated with the compounds were similarly processed and served as controls. High-powered micrographs from multiple distinct low-powered fields in each sample were obtained for the quantitation of damaged cells. Cells that had lost their original shapes and displayed a smooth cell wall were positively scored for damage, such as wrinkling, distortion, and lysis.

\subsection{Membrane Permeability Assay}

The activated bacteria were transferred into LB medium and cultured at $37^{\circ} \mathrm{C}$ until the logarithmic stage $\left(\sim 10^{6} \mathrm{CFU} / \mathrm{mL}\right)$. Respective concentrations of $0.5 \mathrm{MIC}$ and MIC CGA were added to sterile centrifuge tubes after which three parallel samples were collected from each concentration without CGA as a blank control. Furthermore, $0.2 \mathrm{~mL}$ of bacterial solution was taken from each centrifuge tube and mixed well. The initial conductivity in the centrifuge tube was measured as $\mathrm{C}_{0}$ using a conductivity meter after which the solution was cultured at $37^{\circ} \mathrm{C}$, and removed after 2,4 , and $8 \mathrm{~h}$, respectively. Group A was centrifuged at room temperature for $5 \mathrm{~min}$ at 12,000 rpm, while group $\mathrm{B}$ was bathed in water at $100{ }^{\circ} \mathrm{C}$ for $30 \mathrm{~min}$, cooled to room temperature at $12,000 \mathrm{rpm}$, centrifuged at room temperature for $5 \mathrm{~min}$ after which the supernatant was collected. The conductivity of both group $A$ and group $B$ was determined using a conductivity meter, which was denoted as $C_{A}$ and $C_{B}$, 
respectively. The measured conductivity was calculated with a formula where the relative permeability and the permeability of the cell membrane were compared:

$$
\text { Relative permeability }=\frac{C_{A}-C_{0}}{C_{B}-C_{0}} \times 100 \%
$$

\subsection{Measurement of the ATP Content}

The method described by Turgis et al. [38] was followed with some modifications. The working culture of B. subtilis was centrifuged for $5 \mathrm{~min}$ at 12,000 rpm, and the supernatant was removed. The cell pellets were washed three times with PBS (pH 7.4) after which the cells were collected via centrifugation. A cell suspension (OD600 $=0.3 \sim 0.4)$ was prepared with $50 \mathrm{~mL}$ PBS (pH 7.4) after which $4 \mathrm{~mL}$ of the cell solution was placed into an Eppendorf tube for treatment with $0 \mathrm{mg} / \mathrm{mL}$ (control), 0.5 MIC CGA, and MIC CGA, respectively. Samples were maintained at $37^{\circ} \mathrm{C}$ for 2,4 , and $8 \mathrm{~h}$, respectively, and centrifuged for $5 \mathrm{~min}$ at 12,000 rpm. Then the cells were left on ice to prevent ATP loss until measurement of the intracellular ATP concentrations occurred using an ATP assay kit (Beyotime Institute of Biotechnology, Shanghai, China). The ATP cell concentration, which represented the intracellular concentration, was determined using a spectrophotometer (Thermo Scientific ${ }^{\mathrm{TM}}$ Varioskan $^{\mathrm{TM}}$ LUX, Thermo Fisher Scientific Inc., Waltham, MA, USA), following the instructions of the manufacturer.

\subsection{Extraction of the Intracellular Metabolites}

B. subtilis was precultured in LB liquid medium with a rotary speed of $150 \mathrm{rpm}$ at $37^{\circ} \mathrm{C}$ for $12 \mathrm{~h}$. Then, the precultured bacteria cells were transferred to a fresh LB liquid medium, and the initial cell density was adjusted to $0.3-0.4$ at $600 \mathrm{~nm}$. The cells were cultivated at $37^{\circ} \mathrm{C}$ on a rotary shaker at $150 \mathrm{rpm}$ in $250 \mathrm{~mL}$ cotton-plugged flasks containing $100 \mathrm{~mL}$ of LB liquid medium either with or without CGA. Cell samples were collected at 2, 4, and $8 \mathrm{~h}$ either with or without CGA. First, bacteria cells were harvested by centrifugation at 12,000 rpm for $5 \mathrm{~min}$ and washed with PBS three times to remove the residual culture medium, followed by washing with ultrapure water to remove the salts from PBS. Then, we put the cells on dry ice and add $2 \mathrm{~mL}$ of $80 \%(v / v)$ methanol (pre-chilled to $-80^{\circ} \mathrm{C}$ ). Then, cells were broken the cells using sonication under $10{ }^{\circ} \mathrm{C}$ and incubated the lysate at $-80^{\circ} \mathrm{C}$ for $2 \mathrm{~h}$. Then, the metabolite-containing samples were harvested by centrifugation at 12,000 rpm for $10 \mathrm{~min}$ at $4-8{ }^{\circ} \mathrm{C}$, and we collected the metabolite-containing supernatant to a new $1.5-\mathrm{mL}$ tube and prepared for analyses. Three replicates were performed for each sample.

This experiment was analyzed using TSQ Quantiva (Thermo, Waltham, CA, USA). Samples were separated using a Synergi Hydro-RP column $(2.0 \times 100 \mathrm{~mm}, 2.5 \mu \mathrm{m}$, Phenomenex, Torrance, CA, USA). A binary solvent system (mobile phase A, $10 \mathrm{mM}$ tributylamine adjusted with $15 \mathrm{mM}$ acetic acid in water; mobile phase B, methanol) was used. This analysis focused on the TCA cycle, the glycolysis pathway, the pentose phosphate pathway, amino acids, and purine metabolism. A 25 min gradient with a flow rate of $250 \mu \mathrm{L} / \mathrm{min}$ was applied as follows: $1-5 \mathrm{~min}$ at $5 \% \mathrm{~B} ; 5.1-20 \mathrm{~min}, 5-90 \% \mathrm{~B} ; 20.1-25 \mathrm{~min}$, $90 \%$ B. Positive-negative ion switching mode was performed for data acquisition. The resolution for Q1 and Q3 were both 0.7 FWHM. The source voltage was $3500 \mathrm{v}$ for the positive and $2500 \mathrm{v}$ for the negative ion mode. The source parameters were as follows: spray voltage: $3000 \mathrm{v}$; capillary temperature: $320^{\circ} \mathrm{C}$; heater temperature: $300{ }^{\circ} \mathrm{C}$; sheath gas flow rate: 35 ; auxiliary gas flow rate: 10 . Data analysis and quantitation were performed using the TraceFinder 3.2 software (Thermo Fisher, Waltham, CA, USA).

An in-house database for endogenous metabolites identification was created using Library Manager 2.0 (Thermo Fisher Scientific, CA, USA). Most reference spectra in the internal metabolite library were acquired from chemical standards. In some cases, standard metabolites were not accessible but were observed in biological samples. MS/MS spectra of these compounds were confirmed manually according to Metlin (www.metlin.scripps.edu) or HMDB (www.HMDB.ca) and also saved in Library 
Manager for reference. All of the areas of acquired peaks were normalized against the internal standard for further data processing.

\subsection{Statistical Analysis}

All experiments were performed at least three times to obtain the value denoting the average \pm standard deviation (SD). All the areas of acquired peaks were normalized against the internal standard for further data processing. These normalized peak areas (variables) were imported into SIMCA (ver. 14) (Umetrics, Umeå, Sweden) for multivariate statistical analysis. Principal component analysis (PCA) and orthogonal partial least squares discriminant analysis (OPLS-DA) was applied to the data after mean-centering and orthogonal signal correction preprocessing. Moreover, another unsupervised hierarchical cluster analysis (HCA) was performed using the MeV software (4.8). T-tests (SPSS 22) were performed on specific metabolites and their ratios to assess the statistical significance of the metabolic changes.

\section{Conclusions}

In summary, the SEM results indicate that $B$. subtilis cells can remain morphologically almost unchanged after exposure to CGA. The results of the membrane permeability assay, including the leakage of proteins and the solution exosmosis conductivity, indicate that no significant difference is evident after CGA treatment of $B$. subtilis cells. Furthermore, metabolomics analysis reveals that CGA stress leads to the inhibition of metabolic pathways through the suppression of the TCA cycle and glycolysis. Therefore, it is likely that the bacteriostatic action of CGA on B. subtilis may be achieved by inducing intracellular metabolic imbalance.

Author Contributions: Y.W., S.L.: investigation; methodology; collection of test data; writing-original draft. Z.W. (Zhenhua Wang), Z.W. (Ziyuan Wang), X.R.: writing-editing. M.Z.: supervision; project administration; resources. All authors have read and agreed to the published version of the manuscript.

Funding: This research was supported by National Key R\&D Program of China (2019YFC1605905), Projects of Beijing Municipal Science and Technology Project (Grant No. D17110500190000), the Special Project of Beijing Municipal Education Commission and the Beijing Technology and Business University Youth Fund (QNJJ2017-06).

Acknowledgments: The authors thank all colleagues who provided unpublished results and apologize to those whose research was not discussed due to page limitation.

Conflicts of Interest: The authors declare no conflict of interest.

\section{References}

1. Santana-Gálvez, J.; Cisneros-Zevallos, L.; Jacobo-Velázquez, D.A. Chlorogenic acid: Recent advances on its dual role as a food additive and a nutraceutical against metabolic syndrome. Molecules 2017, $22,358$. [CrossRef]

2. Kabir, F.; Katayama, S.; Tanji, N.; Nakamura, S. Antimicrobial effects of chlorogenic acid and related compounds. J. Korean Soc. Appl. Biol. Chem. 2014, 57, 359-365. [CrossRef]

3. Perrone, D.; Donangelo, R.; Donangelo, C.M.; Farah, A. Modeling weight loss and chlorogenic acids content in coffee during roasting. J. Agric. Food. Chem. 2010, 58, 12238-12243. [CrossRef]

4. Awad, M.A.; de Jager, A.; van Westing, L.M. Flavonoid and chlorogenic acid levels in apple fruit: Characterisation of variation. Sci. Hortic. 2000, 83, 249-263. [CrossRef]

5. Sung, W.S.; Lee, D.G. Antifungal action of chlorogenic acid against pathogenic fungi, mediated by membrane disruption. Pure Appl. Chem. 2010, 82, 219-226. [CrossRef]

6. Pedro, M.d.M.; Isabelle, D.; Aurélie, H.; Aurélie, J.; Thomas, R.; Stéphanie, D.; Thérèse, S.; Schneider, Y.J. Anti-inflammatory effect and modulation of cytochrome P450 activities by Artemisia annua tea infusions in human intestinal Caco-2 cells. Food Chem. 2012, 134, 864-871.

7. Wang, G.F.; Shi, L.P.; Ren, Y.D.; Liu, Q.F.; Liu, H.F.; Zhang, R.J.; Li, Z.; Zhu, F.H.; He, P.L.; Tang, W.; et al. Anti-hepatitis B virus activity of chlorogenic acid, quinic acid and caffeic acid in vivo and in vitro. Antiviral Res. 2009, 83, 186-190. [CrossRef] 
8. $\quad$ Bagdas, D.; Etoz, B.C.; Gul, Z.; Ziyanok, S.; Inan, S.; Turacozen, O.; Gul, N.Y.; Topal, A.; Cinkilic, N.; Tas, S.; et al. In vivo systemic chlorogenic acid therapy under diabetic conditions: Wound healing effects and cytotoxicity/genotoxicity profile. Food Chem. Toxicol. 2015, 81, 54-61. [CrossRef]

9. Lou, Z.; Wang, H.; Lv, W.; Ma, C.; Wang, Z.; Chen, S. Assessment of antibacterial activity of fractions from burdock leaf against food-related bacteria. Food Control 2010, 21, 1272-1278. [CrossRef]

10. Fattouch, S.; Caboni, P.; Coroneo, V.; Tuberoso, C.I.G.; Angioni, A.; Dessi, S.; Marzouki, N.; Cabras, P. Antimicrobial activity of tunisian quince (Cydonia oblonga Miller) pulp and peel polyphenolic extracts. J. Agric. Food. Chem. 2007, 55, 963-969. [CrossRef]

11. Kim, B.G.; Jung, W.D.; Mok, H.; Ahn, J.H. Production of hydroxycinnamoyl-shikimates and chlorogenic acid in Escherichia coli: Production of hydroxycinnamic acid conjugates. Microb. Cell Fact. 2013, 12, 15. [CrossRef]

12. Li, G.; Wang, X.; Xu, Y.; Zhang, B.; Xia, X. Antimicrobial effect and mode of action of chlorogenic acid on Staphylococcus aureus. Eur. Food Res. Technol. 2014, 238, 589-596. [CrossRef]

13. Wang, H.; Zhang, S.; Zhao, M.; Li, T. Study on extraction, purification and antimicrobial activity of tobacco chlorogenic acid. Modern Food Sci. Technol. 2008, 3, 233-236.

14. Lou, Z.; Wang, H.; Zhu, S.; Ma, C.; Wang, Z. Antibacterial activity and mechanism of action of chlorogenic acid. J. Food Sci. 2011, 76, M398-M403. [CrossRef]

15. Su, M.; Sun, Z.; Liu, F.; Wu, H.; Zhang, X.; Zhu, Y.; Daoying, W.; Xu, W.; Luo, Z. Antimicrobial mechanism of chlorogenic acid against chicken spoilage bacteria. Jiangsu J. Agric. Sci. 2018, 34, 1386-1391.

16. Kono, Y.; Kobayashi, K.; Tagawa, S.; Adachi, K.; Ueda, A.; Sawa, Y.; Shibata, H. Antioxidant activity of polyphenolics in diets: Rate constants of reactions of chlorogenic acid and caffeic acid with reactive species of oxygen and nitrogen. BBA Gen. Subjects 1997, 1335, 335-342. [CrossRef]

17. Francisco, V.; Costa, G.; Figueirinha, A.; Marques, C.; Pereira, P.; Miguel Neves, B.; Celeste Lopes, M.; García-Rodríguez, C.; Teresa Cruz, M.; Teresa Batista, M. Anti-inflammatory activity of cymbopogon citratus leaves infusion via proteasome and nuclear factor- $\mathrm{kB}$ pathway inhibition: Contribution of chlorogenic acid. J. Ethnopharmacol. 2013, 148, 126-134. [CrossRef]

18. Ren, S.; Wu, M.; Guo, J.; Zhang, W.; Liu, X.; Sun, L.; Holyst, R.; Hou, S.; Fang, Y.; Feng, X. Sterilization of polydimethylsiloxane surface with Chinese herb extract: A new antibiotic mechanism of chlorogenic acid. Sci. Rep. 2015, 5, 10464. [CrossRef]

19. Craig, H. Food-related illness and death in the United States. Emerg. Infect. Dis. 1999, 5, 840.

20. Batt, C.A. Microbial food spoilage. In Reference Module in Food Science; Elsevier: Amsterdam, The Netherlands, 2016.

21. André, S.; Vallaeys, T.; Planchon, S. Spore-forming bacteria responsible for food spoilage. Res. Microbiol. 2017, 168, 379-387. [CrossRef]

22. Batt, C.A. Microbial Food Spoilage. 2016. Available online: https://doi.org/10.1016/B978-0-08-100596-5.034405 (accessed on 1 July 2016).

23. $\mathrm{Xu}, \mathrm{Y}$;; $\mathrm{Xu}, \mathrm{X}$.; Xin, S. Separation and identification of spoilage microorganisms in instant wet noodles. China Brew 2014, 33, 68-71.

24. Wang, X.M.; Chen, J.; Ying-Guo, L.V.; Liu, Z.L. Research progress of preservation technology for fresh noodles. Cereals Oils 2013, 26, 12-15.

25. Fiehn, O. Metabolomics-the link between genotypes and phenotypes. Plant Mol. Biol. 2002, 48, $155-171$. [CrossRef]

26. Saghatelian, A.; Cravatt, B.F. Global strategies to integrate the proteome and metabolome. Curr. Opin. Chem. Biol. 2005, 9, 62-68. [CrossRef]

27. Ding, M.Z.; Wang, X.; Yang, Y.; Yuan, Y.J. Metabolomic study of interactive effects of phenol, furfural, and acetic acid on saccharomyces cerevisiae. OMICS J. Integrative Biol. 2011, 15, 647-653. [CrossRef]

28. Ravenzwaay, B.; Cunha, G.C.-P.; Leibold, E.; Looser, R.; Mellert, W.; Prokoudine, A.; Walk, T.; Wiemer, J. The use of metabolomics for the discovery of new biomarkers of effect. Toxicol. Lett. 2007, 172, 21-28. [CrossRef]

29. Omelon, S.; Georgiou, J.; Habraken, W. A cautionary (spectral) tail: Red-shifted fluorescence by DAPI-DAPI interactions. Biochem. Soc. Trans. 2016, 44, 46-49. [CrossRef]

30. Bo, T.; Liu, M.; Zhong, C.; Zhang, Q.; Su, Q.Z.; Tan, Z.L.; Han, P.P.; Jia, S.R. Metabolomic analysis of antimicrobial mechanisms of $\varepsilon$-Poly-l-lysine on saccharomyces cerevisiae. J. Agric. Food. Chem. 2014, 62, 4454-4465. [CrossRef] 
31. Bylesjö, M.; Rantalainen, M.; Cloarec, O.; Nicholson, J.K.; Holmes, E.; Trygg, J. OPLS discriminant analysis: Combining the strengths of PLS-DA and SIMCA classification. J. Chemom. 2006, 20, 341-351. [CrossRef]

32. Halouska, S.; Fenton, R.J.; Barletta, R.G.; Powers, R. Predicting the in vivo mechanism of action for drug leads using NMR metabolomics. ACS Chem. Biol. 2012, 7, 166-171. [CrossRef]

33. Zhu, Z.; Wang, H.; Shang, Q.; Jiang, Y.; Cao, Y.; Chai, Y. Time course analysis of Candida albicans metabolites during biofilm development. J. Proteome Res. 2013, 12, 2375-2385. [CrossRef] [PubMed]

34. Luo, Y.; Huang, L.; Yang, Y.; Zhu, M.; Wen, Y.; Liu, Y.; Zhang, R.; Liu, J. Study on the mechanism of chlorogenic acid inhibiting Staphylococcu saureus. J. Southwest Univ. 2016, 38, 15-19.

35. Barsch, A.; Carvalho, H.G.; Cullimore, J.V.; Niehaus, K. GC-MS based metabolite profiling implies three interdependent ways of ammonium assimilation in Medicago truncatula root nodules. J. Biotechnol. 2006, 127, 79-83. [CrossRef] [PubMed]

36. Li, H.; Ma, M.; Luo, S.; Zhang, R.; Han, P.; Hu, W. Metabolic responses to ethanol in Saccharomyces cerevisiae using a gas chromatography tandem mass spectrometry-based metabolomics approach. Int. J. Biochem. Cell Biol. 2012, 44, 1087-1096. [CrossRef]

37. Govaris, A.; Solomakos, N.; Pexara, A.; Chatzopoulou, P.S. The antimicrobial effect of oregano essential oil, nisin and their combination against Salmonella Enteritidis in minced sheep meat during refrigerated storage. Int. J. Food Microbiol. 2010, 137, 175-180. [CrossRef]

38. Turgis, M.; Han, J.; Caillet, S.; Lacroix, M. Antimicrobial activity of mustard essential oil against Escherichia coli O157:H7 and Salmonella typhi. Food Control 2009, 20, 1073-1079. [CrossRef]

Sample Availability: Samples of the compounds are not available from the authors.

(C) 2020 by the authors. Licensee MDPI, Basel, Switzerland. This article is an open access article distributed under the terms and conditions of the Creative Commons Attribution (CC BY) license (http://creativecommons.org/licenses/by/4.0/). 